\title{
Solution-Processed Highly Efficient Semitransparent Organic Solar Cells with Low Donor Contents
}

\author{
Nannan Yao, Yuxin Xia,* Yanfeng Liu, Shangzhi Chen, Magnus P. Jonsson, and Fengling Zhang* \\ Cite This: ACS Appl. Energy Mater. 2021, 4, 14335-14341 \\ Read Online
}

ACCESS | Lلll Metrics \& More | 回 Article Recommendations | si Supporting Information

\begin{abstract}
Semitransparent organic solar cells (ST-OSCs) are promising candidates for applications in building-integrated photovoltaics (BIPV) as windows and facades. The challenge to achieve highly efficient ST-OSCs is the trade-off between power conversion efficiency (PCE) and average visible transmittance (AVT). Herein, solution-processed ST-OSCs are demonstrated on the basis a polymer donor, PM6, and a small molecule acceptor, Y6; lowering the visible-absorbing PM6 contents in blends could increase AVT and maintain PCE. Additionally, conductive polymer PEDOT:PSS is used as the top electrode due to its high transparency, good conductivity, and solution processability. Efficient ST-OSCs with 20 wt \% PM6 achieve high PCE of
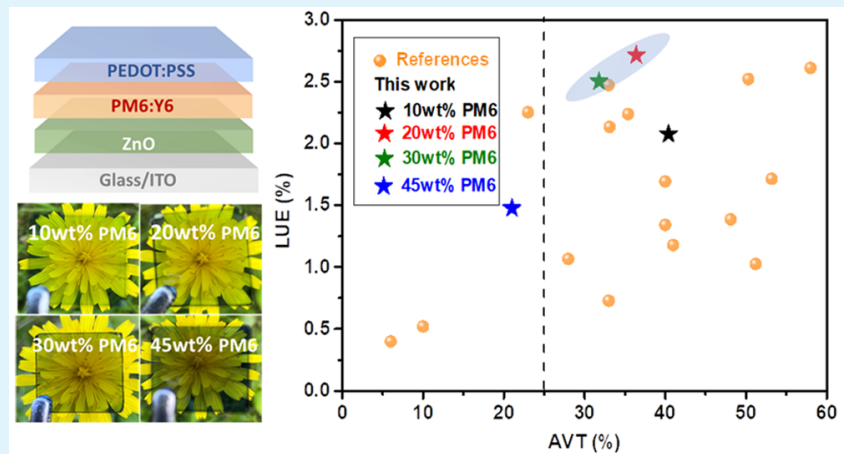
$7.46 \%$ and AVT of $36.4 \%$. The light utilization efficiency (LUE) of $2.72 \%$ is among the best reported values for solution-processed ST-OSCs. This work provides a straightforward approach for solution-processed ST-OSCs by combining a low fraction of visible-wavelength-selective polymer donors with near-infrared nonfullerene acceptors to achieve high PCE and AVT simultaneously.
\end{abstract}

KEYWORDS: semitransparent organic solar cells, low-fraction visible-absorbing donor, near-infrared-absorbing acceptor, light utilization efficiency, solution processability

\section{INTRODUCTION}

Building-integrated photovoltaics (BIPV) as electrical power generators are directly integrated into buildings to replace conventional building materials. ${ }^{1}$ The underutilized surface area of buildings such as facades and windows with integrated semitransparent photovoltaic devices can offer a large area for light harvesting and help one to realize net zero energy consumption. ${ }^{2,3}$ An ideal semitransparent device should absorb most ultraviolet (UV) and near-infrared (NIR) photons, while transmitting visible light $(380-700 \mathrm{~nm})$. Organic solar cells (OSCs) with tunable optical properties and solution processability have been previously demonstrated as good candidates for power-generating windows. ${ }^{4-7}$

The challenge for semitransparent-OSCs (ST-OSCs) is that power conversion efficiency (PCE) and average visible transmission (AVT) need to be simultaneously optimized, as there is a trade-off between light absorption and transmission. Recently, the PCEs of ST-OSCs have reached over $13 \%$ with AVTs around $22 \%{ }^{8,9}$ However, depending on applications, generally, the AVT of ST-OSCs should exceed $25 \%$ to meet the requirement for solar windows. ${ }^{5,10,11}$ Furthermore, to objectively evaluate ST-OSCs, light utilization efficiency (LUE) defined as the product of PCE and AVT has been introduced. ${ }^{12,13}$ The LUE of $2-4 \%$ for efficient ST-OSCs has been reported, while the solution-processed ST-OSCs have realized high LUE around $2.5 \%{ }^{14-16}$

To maintain high transparency, a transparent electrode is an essential part of ST-OSCs. Currently, many articles have demonstrated high-performance ST-OSCs by employing vacuum deposited thin metallic films as top electrodes. ${ }^{8,17,18}$ However, compared to evaporated metal electrodes, solution processable, cost-effective electrodes deposited at low temperature are more desirable for upscale industrialization of STOSCs. ${ }^{19-21}$ Alternative top electrodes such as graphene, conductive polymers, and $\mathrm{Ag}$ nanowires have been widely applied in ST-OSCs. ${ }^{22-24}$ Among these materials, conductive polymer poly(3,4-ethylenedioxythiophene)-poly(styrenesulfonate) (PEDOT:PSS; Clevios PH1000) has high transparency in the visible range, good conductivity, and lowtemperature solution processability, enabling PEDOT:PSS as an advantage for applications in ST-OSCs. ${ }^{25-30}$

Received: September 27, 2021

Accepted: November 8, 2021

Published: November 17, 2021 
(a)
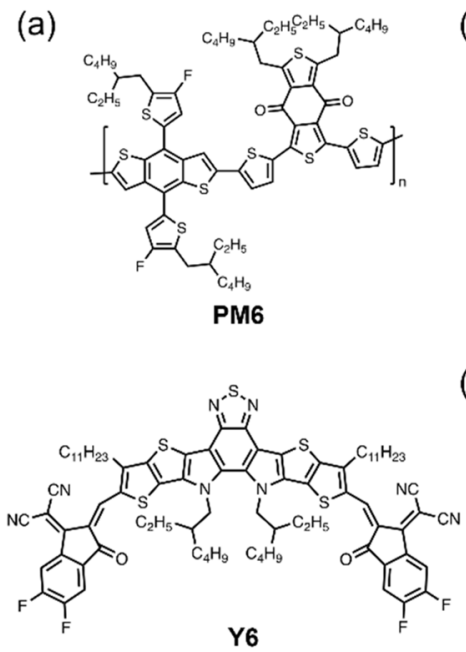

(b)

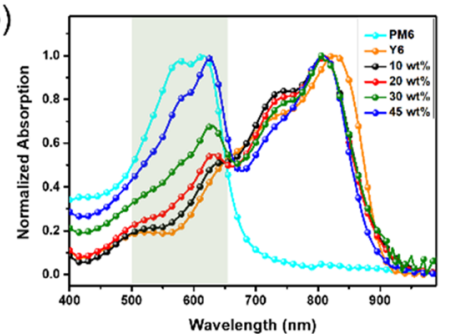

(c)

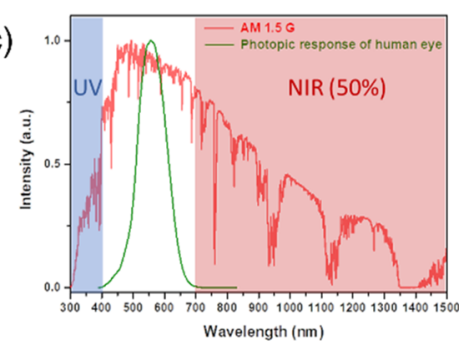

(d)
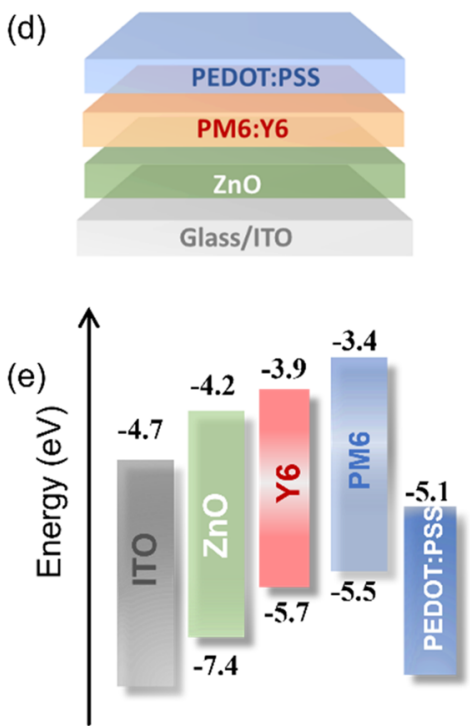

Figure 1. (a) Molecular structures of the donor PM6 and acceptor Y6. (b) Absorption spectra of PM6, Y6, and PM6:Y6 blends with different PM6 contents (absorption of blend films was normalized at acceptor's peak). (c) AM 1.5G solar spectrum (red line) and photopic response of human eyes (green line). (d) Device architecture of inverted ST-OSCs:ITO/ZnO/PM6:Y6/PEDOT:PSS. (e) Energy level diagram of the ST-OSCs.

(a)

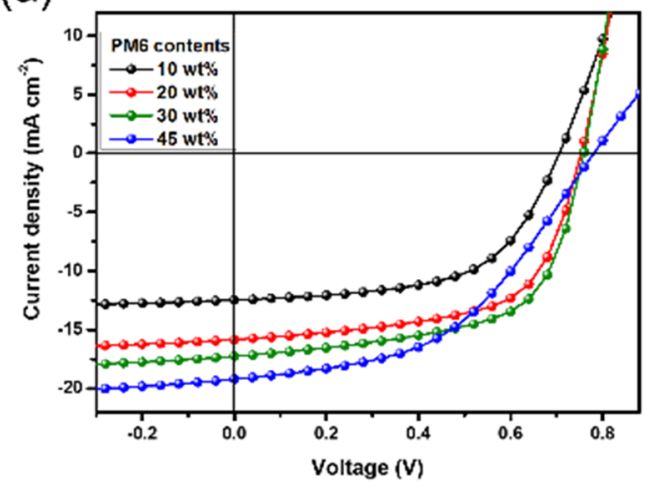

(b)

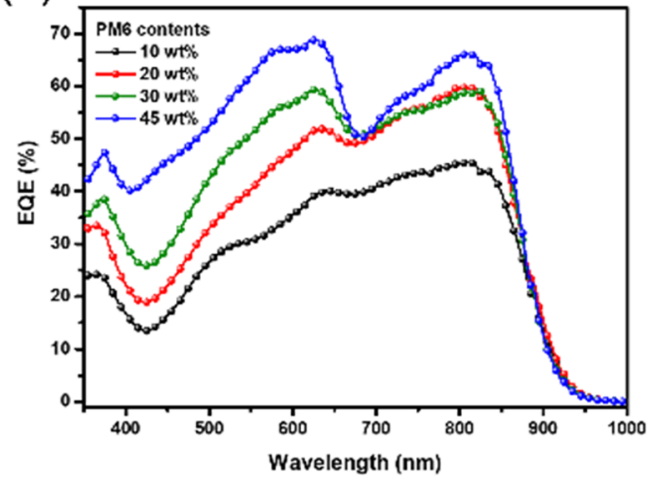

Figure 2. (a) $J-V$ curves and (b) EQE spectra of PM6:Y6 ST-OSCs with 10, 20, 30, and 45 wt \% PM6 contents (illumination from ITO).

To achieve efficient ST-OSCs with high visible transmittance, in addition to employing transparent electrodes, many strategies have also been focused on investigating active layers. ${ }^{31-33}$ Controlling the thickness of the active layers is one way to balance AVT and PCE, where decreasing thickness improves AVT at the cost of photovoltaic performance. Additionally, some nonfullerene acceptors (NFAs) with narrow band gap can selectively absorb NIR light, ${ }^{34,35}$ which potentially enables the optimal photon harvesting of active layers with visible light transmission. ST-OSCs fabricated with NIR light-selective NFAs makes it possible to achieve high PCE with AVT. Among commercial NFAs, Y6 with a narrow band gap of $1.33 \mathrm{eV}$ and strong NIR absorption coefficient of $1.07 \times 10^{5} \mathrm{~cm}^{-1}$ is a good candidate. ${ }^{36}$ We observed that the photovoltaic performance of single-junction PM6:Y6 solar cells (opaque devices) exhibiting high tolerance to the donor contents from 10 to 45 wt $\%$ and dilute donor solar cells can still maintain efficient charge generation and collection. ${ }^{37,38}$ Most polymer donors absorb visible light; ${ }^{39,40}$ it is thereby possible to control the transparency in the visible range without compromising photovoltaic performance by tuning the donor content.
Herein, solution-processed ST-OSCs with an inverted structure of ITO/ZnO/PM6:Y6/PEDOT:PSS (Clevios PH1000) were fabricated. PEDOT:PSS with high transmittance of around $80 \%$ and a conductivity of $510 \mathrm{~S} \mathrm{~cm}^{-1}$ was used as hole transport layer and top electrode. Our results show that PM6:Y6 blends with low contents of PM6 (10-30 wt \%) could maintain high transparency in the visible range as PM6 mainly absorbs visible light. ST-OSCs with low donor contents exhibit high AVT over $30 \%$ and PCE around $7 \%$. A LUE of $2.72 \%$, among the highest values of solution processable ST-OSCs, was achieved with the ST-OSCs based on $20 \mathrm{wt} \%$ PM6. The results suggest that reducing the visibleabsorbing donors contents in polymer/NFA blends is a feasible strategy for efficient ST-OSCs with balanced PCE and AVT to overcome the contradictory requirements for the absorbers.

\section{RESULTS AND DISCUSSION}

The molecular structures of PM6 and Y6 are shown in Figure 1a. The pristine PM6 absorbs visible light (500-650 nm), while Y6 mainly absorbs NIR photons (700-850 nm), as illustrated in Figure 1b. PM6:Y6 blend films with lower PM6 contents $(<45$ wt \%) absorb a relatively low fraction of visible light $(500-650 \mathrm{~nm})$, which is the most sensitive spectral part 
Table 1. Summary of Representative Solution-Processed ST-OSCs with Corresponding Photovoltaic Parameters, AVT and LUE $^{a}$

\begin{tabular}{|c|c|c|c|c|c|c|c|}
\hline device architecture & $\begin{array}{c}J_{\mathrm{SC}} \\
\left(\mathrm{mA} \mathrm{cm}_{-2}\right)\end{array}$ & $\begin{array}{l}V_{\mathrm{OC}} \\
(\mathrm{V})\end{array}$ & FF & PCE (\%) & $\begin{array}{c}\text { AVT } \\
(\%)\end{array}$ & $\begin{array}{l}\text { LUE } \\
(\%)\end{array}$ & ref \\
\hline ITO/ZnO/PM6:Y6/PEDOT:PSS (10 wt \% PM6, 95 nm) & 12.5 & 0.71 & 0.58 & $5.14(5.08)$ & 40.4 & 2.01 & $\begin{array}{l}\text { this } \\
\text { work }\end{array}$ \\
\hline ITO/ZnO/PM6:Y6/PEDOT:PSS (20 wt \% PM6, 100 nm) & 15.8 & 0.75 & 0.63 & $7.46(7.27)$ & 36.4 & 2.72 & $\begin{array}{l}\text { this } \\
\text { work }\end{array}$ \\
\hline ITO/ZnO/PM6:Y6/PEDOT:PSS (30 wt \% PM6, 102 nm) & 17.2 & 0.75 & 0.61 & $7.87(7.45)$ & 31.8 & 2.50 & $\begin{array}{l}\text { this } \\
\text { work }\end{array}$ \\
\hline ITO/ZnO/PM6:Y6/PEDOT:PSS (45 wt \% PM6, 125 nm) & 19.2 & 0.78 & 0.47 & $7.04(6.71)$ & 21.0 & 1.48 & $\begin{array}{l}\text { this } \\
\text { work }\end{array}$ \\
\hline ITO/ZnO/PM6:Y6/PEDOT:PSS (45 wt \% PM6, 90 nm) & 14.3 & 0.80 & 0.48 & $5.51(5.20)$ & 31.1 & 1.71 & $\begin{array}{l}\text { this } \\
\text { work }\end{array}$ \\
\hline ITO/PEDOT:PSS/PBDBT-SeDPP:PC ${ }_{71} \mathrm{BM} / \mathrm{TiO}_{2} / \mathrm{AgNW}$ & 11.5 & 0.72 & 0.55 & 4.5 & 58 & 2.61 & 15 \\
\hline ITO/ZnO/PffBT4T-2OD:PC ${ }_{71}$ BM/PEDOT:PSS:PMA/AgNWs & 11.28 & 0.78 & 0.57 & 5.01 & 50.3 & 2.52 & 16 \\
\hline PDMS/PMMA/graphene/PEDOT:PSS/PTB7:PC ${ }_{71} \mathrm{BM} / \mathrm{ZnO}-\mathrm{NP} / \mathrm{PEDOT}: \mathrm{PSS} /$ graphene/glass & 12.1 & 0.67 & 0.41 & 3.35 & 40 & 1.34 & 24 \\
\hline PDMS/PMMA/graphene/PEDOT:PSS/PTB7:PC ${ }_{71} \mathrm{BM} / \mathrm{ZnO}-\mathrm{NP} / \mathrm{ITO} /$ glass & 11.84 & 0.67 & 0.53 & 4.23 & 40 & 1.69 & 24 \\
\hline ITO/ZnO NP/PTB7-Th:EH-IDTBR/PEDOT:PSS/IL & 11.35 & 0.98 & 0.57 & 6.32 & 35.4 & 2.24 & 29 \\
\hline ITO/ZnO/PEIE/P3HT:PC ${ }_{61} \mathrm{BM} / \mathrm{PH} 1000 / \mathrm{AI} 4083 / \mathrm{EG}$ & 6.9 & 0.58 & 0.51 & 2.0 & 51.2 & 1.02 & 30 \\
\hline ITO/ZnO/PTB7-Th:IEICO-4F/PEDOT:PSS/AgNWs & 17.78 & 0.66 & 0.61 & 7.49 & 33 & 2.47 & 42 \\
\hline ITO/ZnO/PM6:Y6/PEDOT:PSS/AgNWs & 20.84 & 0.72 & 0.61 & 9.79 & 23 & 2.25 & 42 \\
\hline AgNWs/AZO/P3HT:Si-PCPDTBT:PC ${ }_{61}$ BM/PEDOT:PSS/AgNWs & 6.4 & 0.56 & 0.6 & 2.20 & 33 & 0.73 & 43 \\
\hline glass/AgNWs/PEDOT:PSS/pDPP5T-2:PCBM/ZnO/AgNWs & 8.24 & 0.56 & 0.61 & 2.87 & 41 & 1.17 & 44 \\
\hline ITO/PEIE/P3HT:IDT-2BR/PH1000-T & 6.23 & 0.84 & 0.61 & 3.22 & 53.2 & 1.71 & 45 \\
\hline PES/PH1000/PEIE/P3HT:IDT-2BR/PH1000-T & 5.93 & 0.84 & 0.58 & 2.88 & 48.1 & 1.39 & 45 \\
\hline PET/Ag mesh/PEDOT:PSS/ZnO/PffBT4T-2OD:PC ${ }_{61}{\mathrm{BM}: P C_{71} \mathrm{BM} / \mathrm{PEDOT}: \mathrm{PSS}: \mathrm{AgNW}}$ & 13.9 & 0.75 & 0.62 & 6.6 & 6 & 0.4 & 46 \\
\hline ITO/ZnO/PBTZT-stat-BDTT-8:PC 61 BM/PEDOT:PSS:AgNW & 10.6 & 0.72 & 0.5 & 3.8 & 28 & 1.06 & 47 \\
\hline FTO/ZnO/PBTZT-stat-BDTT-8:PC 60 BM/PEDOT:PSS (Clevios FHC)/AgNWs & 9.40 & 0.80 & 0.69 & 5.18 & 10 & 0.52 & 48 \\
\hline PET/IMI/ZnO/PBTZT-stat-BDTT-8:PC ${ }_{60} \mathrm{BM} / \mathrm{PEDOT}: \mathrm{PSS}$ (Clevios FHC)/AgNWs & 8.8 & 0.8 & 0.59 & 4.1 & 15 & 0.62 & 48 \\
\hline ITO/ZnO/PBDBD-2Cl:IT4F/MoOx/AgNW & 11.44 & 0.84 & 0.67 & 6.44 & 33.12 & 2.13 & 49 \\
\hline
\end{tabular}

${ }^{a}$ The PCE in brackets is the average value for 10 devices.

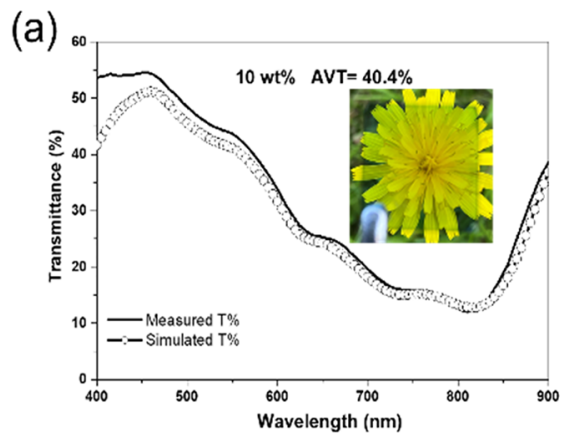

(b)

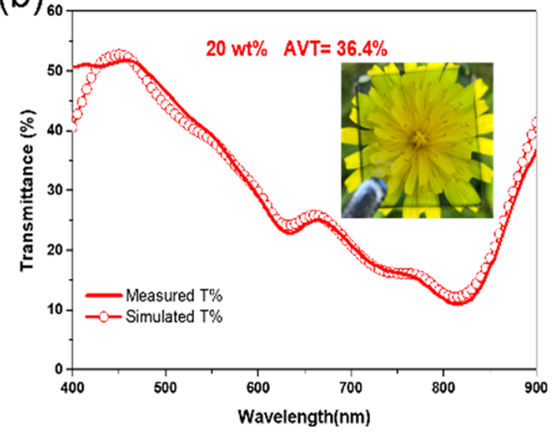

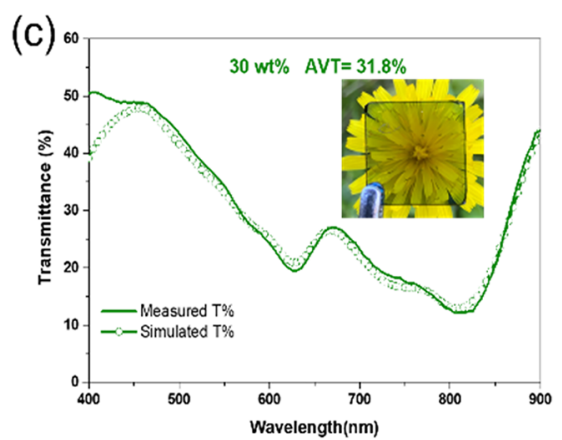

$(d)_{6}$

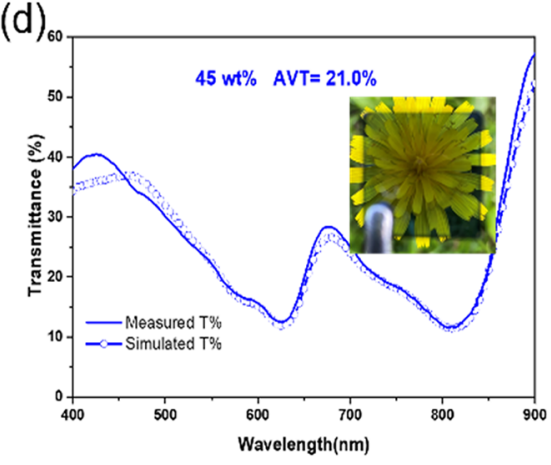

(e)

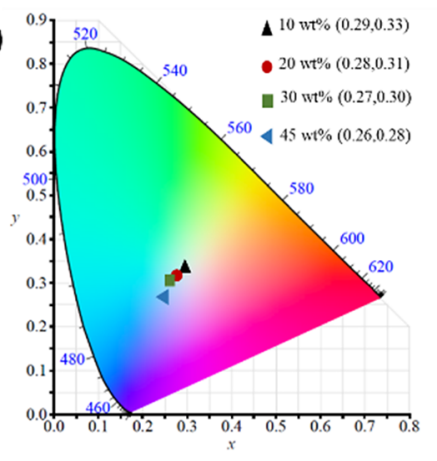

(f)

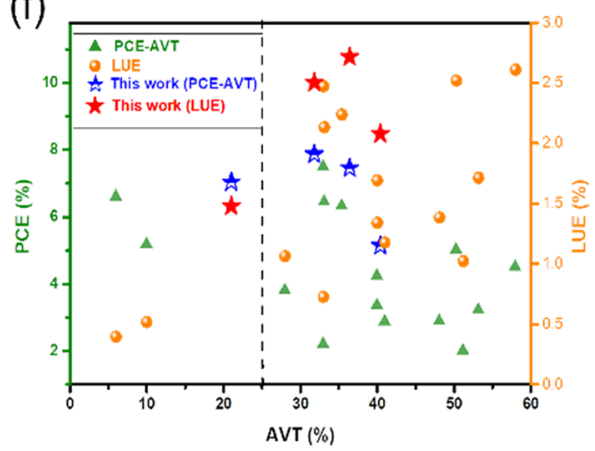

Figure 3. Transmission spectra of PM6:Y6 ST-OSCs with (a) 10, (b) 20, (c) 30, and (d) 45 wt \% PM6. The corresponding simulated curves are plotted as open circles. Photographs of corresponding PM6:Y6 ST-OSCs were inserted into panels a-d. (e) CIE 1931 chromaticity diagram: color coordinates of ST-OSCs with 10, 20, 30, and 45 wt \% PM6. (f) Overview on photovoltaic performance and optical properties in solution-processed ST-OSCs. 
of human eyes (Figure 1c). As shown in Figure 1c, the AM1.5G solar spectrum consists of $47 \%$ visible and $50 \%$ NIR photon flux. Therefore, for OSCs with NIR absorption, it is possible to achieve comparable performance to devices with $\mathrm{UV}$ and visible absorption. In addition, the transmittance of PEDOT:PSS film with thickness of $170 \mathrm{~nm}$ is around $80 \%$ in the visible range (see Supporting Information Figure S1). This relatively high transmittance can meet the requirement for STOSCs. The work function of the PEDOT:PSS films is around $5.1 \mathrm{eV}^{41}$ which enables PEDOT:PSS to work as both hole transport layer and top electrode simultaneously. To study the device performance, the ST-OSCs were fabricated with an inverted structure of ITO/ZnO/PM6:Y6/PEDOT:PSS (Figure 1d). The corresponding energy levels of materials in the ST-OSCs are shown in Figure 1e.

Current density-voltage $(J-V)$ curves and external quantum efficiency (EQE) spectra of PM6:Y6 ST-OSCs with different PM6 contents illuminated from the ITO side are plotted in Figure 2. A matte black background was used in measurement to avoid overestimation. As shown, the short circuit current density $\left(J_{\mathrm{sc}}\right)$ increases with the PM6 content, as more visible light is absorbed. ST-OSCs with $10 \mathrm{wt} \%$ PM6 show the lowest $J_{\mathrm{sc}}$ of $12.5 \mathrm{~mA} \mathrm{~cm} \mathrm{~cm}^{-2}$ and PCE of $5.14 \%$, while the optimized devices with 20,30, and 45 wt \% PM6 exhibit higher $J_{\mathrm{sc}}\left(>15 \mathrm{~mA} \mathrm{~cm}^{-2}\right)$ and PCE over $7 \%$ (Table 1).

In addition to optimizing PCEs of the devices, it is also essential to achieve high visible transparency in ST-OSCs. Panels a-d of Figure 3 present the photographs and measured transmittances of corresponding PM6:Y6 ST-OSCs. Additionally, the transmittances of all ST-OSCs were simulated with the transfer matrix method (TMM) according to procedures described in detail in the literature. ${ }^{50-52}$ The refractive index $(n)$ and the extinction coefficient $(k)$ of the functional layers were obtained by ellipsometry (see Figure S2). The simulations show a good match with the experimental data (Figure $3 \mathrm{a}-\mathrm{d}$ ), which also implies that TMM simulation forms a useful tool for ST-device design. The thicknesses of functional layers used in TMM can be found in Table S2, which are based on the measured thicknesses by Dektak profilometer within an error of $10 \mathrm{~nm}$.

The transmittance results show that, except for the $45 \mathrm{wt} \%$ PM6:Y6 device, all of these devices with low donor contents present high AVT over 30\%. In order to achieve an AVT over $30 \%$ for 45 wt \% PM6:Y6 ST-OSCs, results from the TMM simulations were used, which indicated that the thickness of the active layer should be around $95 \mathrm{~nm}$ (Table S3). Indeed, the experimental data show that when the thickness of $45 \mathrm{wt} \%$ PM6:Y6 film is reduced to $90 \mathrm{~nm}$, an AVT of $31.1 \%$ could be obtained, although with lower PCE of 5.51\% (Figure S3 and Table S4), and the LUE of $1.71 \%$ is lower than that of the best ST-OSCs with 20 wt \% PM6 (LUE $=2.72 \%$, Table 1 ). The lower fill factor (FF) of 45 wt \% PM6:Y6 ST-OSCs present in this work might be due to the involvement of unexpected substances such as water or additives from PEDOT:PSS solution during the spin-coating process for PEDOT:PSS. Because FFs are higher in dilute donor ST-OSCs, we suspect that PM6 is more plausible to be affected by such issues, e.g., creating traps, and to occur at the interface with PEDOT:PSS rather than in bulk, as both thin $(90 \mathrm{~nm})$ and thick $(125 \mathrm{~nm})$ active layer devices show similar low FF. To compare in a fair way with 20 wt \% PM6:Y6 devices, the TMM model was used to simulate the performance of both 20 and 45 wt \% PM6:Y6 ST-OSCs, where the FF was set to $60 \%$ and internal quantum efficiency (IQE) was set to $100 \%$ with a set of different active layer thicknesses (Table S3). It shows that even if the FF in 45 wt \% PM6:Y6 devices is as high as in the devices with $20 \mathrm{wt} \%$ PM6, the simulated LUE of 20 wt \% PM6:Y6 is still higher for all investigated active layer thicknesses.

Furthermore, it is important to develop almost neutralcolored devices for power-generating windows. To quantify the color neutrality of ST-OSCs, we converted the transmittance spectra of the different ST-OSCs to CIE color coordinates to evaluate the color of light transmitted through the devices. STOSCs with 10, 20, and 30 wt \% PM6 show color coordinates of $(0.29,0.33),(0.28,0.31)$, and $(0.27,0.30)$, respectively, which are close to the color coordinates of the AM1.5G solar spectrum $(0.32,0.33)$, representing good color neutrality (Figure 3e).

Although PCE is often inversely related to AVT, LUE is an objective parameter to compare the performance of different ST devices. Comparing our ST-OSCs with different donor contents, the 20 wt \% PM6 device exhibited the largest LUE of $2.72 \%$. On the basis of the overview of previous articles on solution-processed ST-OSCs summarized in Figure $3 \mathrm{f}$ and Table 1, the LUE of $2.72 \%$ is unprecedented. Our work highlights that the dilute donor strategy not only can achieve high transmittance in the visible region but also maintain efficient photovoltaic performance for ST-OSCs, even using a simple device configuration with only PEDOT:PSS as the top electrode.

It is notable that the ST-OSCs show better photovoltaic performance when illuminated from the ITO side than from the PEDOT:PSS side (Figure S4 and Table S5), which is attributed to the higher transmittance of ITO than that of PEDOT:PSS. Indeed, simulated absorption spectra of the active layer plotted in Figure S4 demonstrate that ST-OSCs illuminated from the PEDOT:PSS side have less NIR photons absorbed by the active layer and, thereby, lower $J_{\text {sc }}$ and EQE.

Our work suggests that lowering the amount of polymer donors in blends that contain NIR-absorbing small molecular acceptors could be a general straightforward approach for efficient ST-OSCs. As for the dilute donor structure, two important issues should be considered: charge transfer and charge transport. Some previous studies have shown that, in dilute donor blends, large amounts of small molecule acceptors tend to aggregate and form large phase sizes; ${ }^{53}$ therefore, a long exciton lifetime of acceptors is required to achieve efficient charge generation in dilute donor devices. As for charge transport, we summarized some previous studies as shown in Figure S5; dilute donor devices exhibit relatively balanced hole and electron transport properties, indicating hole transport is not a limitation.

\section{CONCLUSIONS}

In summary, solution-processed ST-OSCs with an inverted structure of ITO/ZnO/PM6:Y6/PEDOT:PSS were fabricated. Efficient PM6:Y6 ST-OSCs based on dilute donor structure (20 wt \% PM6) achieved PCE of $7.46 \%$, AVT of $36.4 \%$, and LUE of $2.72 \%$, which is among the best reported solutionprocessable ST-OSCs. Our work demonstrates that ST-OSCs comprising low-fraction visible-absorbing polymer donors with near-infrared-absorbing acceptors can simultaneously achieve high PCE and AVT, which provides a simple strategy for largescale production of efficient ST-OSCs for power-generating windows in the future. 


\section{EXPERIMENTAL SECTION}

4.1. Materials. PM6 was purchased from Solarmer, Inc. (Beijing). Y6 was purchased from The Hong Kong University of Science and Technology (HKUST). $\mathrm{ZnO}(\mathrm{N}-10,2.5 \mathrm{wt} \%$ in isopropanol) was purchased from Avantama. All materials were used as received without additional purification. PEDOT:PSS was purchased from Heraeus (CLEVIOS PH1000). The molecular weights of PM6 used in this work are $M_{\mathrm{n}} 45 \mathrm{kDa}$ and $M_{\mathrm{w}} 97 \mathrm{kDa}$, with PDI $=2.16$.

4.2. Device Fabrication. The ITO-coated glasses were cleaned by detergent and then treated by TL-1 with a mixture of water, ammonia, and hydrogen peroxide (volume ratio, 5:1:1). ITO substrates were further dried by $\mathrm{N}_{2}$ flow. Before $\mathrm{ZnO}$ layer deposition, $\mathrm{ZnO}$ nanoparticle dispersion in isopropanol (2.5 wt \%) was ultrasonicated in an ultrasonic bath for $10 \mathrm{~min}$ to get rid of any aggregates. Then, $\mathrm{ZnO}$ was spin-coated on ITO at $3500 \mathrm{rpm}$ for $40 \mathrm{~s}$, followed by annealing at $120{ }^{\circ} \mathrm{C}$ for $30 \mathrm{~min}$ in air. PM6:Y6 with different donor concentrations were dissolved in chloroform with a total concentration of $16 \mathrm{mg} / \mathrm{mL}$. $0.5 \% \mathrm{CN}$ (volume ratio) was used as an additive in blend solutions. The solutions were stirred at $40{ }^{\circ} \mathrm{C}$ for $6 \mathrm{~h}$ before spin-coating. The active layers were subsequently spincoated on ITO $/ \mathrm{ZnO}$ and then were thermally annealed at $110^{\circ} \mathrm{C}$ for $10 \mathrm{~min}$ in a glovebox. To prepare PEDOT:PSS electrode, 5\% EG and $0.2 \%$ FS-300 (volume ratios) were added in PEDOT:PSS aqueous solution (PH1000, Heraeus Clevios), followed by stirring at room temperature for $4 \mathrm{~h}$. The mixture solution was filtered through a 0.45 $\mu \mathrm{m}$ syringe filter and then spin-coated on the active layers at 1500 rpm for $60 \mathrm{~s}$ as the top electrode. The spin-coating process repeats twice to get a thickness around $170 \mathrm{~nm}$. Finally, the devices were annealed at $90{ }^{\circ} \mathrm{C}$ for $5 \mathrm{~min}$ to remove residual water. The effective device area is $0.1 \mathrm{~cm}^{2}$.

4.3. Characterizations. The $J-V$ curves were characterized by a Keithley 2400 source meter with AM1.5G solar simulator at an intensity of $100 \mathrm{~mW} \mathrm{~cm} \mathrm{~cm}^{-2}$. The EQE spectra were recorded using a Newport Merlin lock-in amplifier. Refractive indices and extinction coefficients of pristine and blend organic films are measured with variable angle spectroscopic ellipsometry for incident angles of 55, 65, and $75^{\circ}$ using an RC2 ellipsometer from J. A. Woollam Co., Inc. Transmission spectra of semitransparent devices and electrodes were measured by a PerkinElmer Lambda 900 UV-vis-NIR spectrometer. The test beam spot is smaller than the device area. AVT is determined by calculating the average value of transmittance of the semitransparent device in the visible light range $(380-780 \mathrm{~nm})$ on the basis of the photonic response of the human eye. The AVT value of semitransparent OSCs can be calculated according to the following equation:

$$
\operatorname{AVT}=\frac{\int T(\lambda) V(\lambda) \operatorname{AM} 1.5 \mathrm{G}(\lambda) \mathrm{d}(\lambda)}{\int V(\lambda) \operatorname{AM1.5G}(\lambda) \mathrm{d}(\lambda)}
$$

where $\lambda$ is the wavelength, $T(\lambda)$ is the transmission of the semitransparent solar cells, $V(\lambda)$ is the photopic response of the human eyes, and $\operatorname{AM1.5G}(\lambda)$ is the solar spectral irradiance.

\section{ASSOCIATED CONTENT}

\section{SI Supporting Information}

The Supporting Information is available free of charge at https://pubs.acs.org/doi/10.1021/acsaem.1c03017.

Transmission spectra; thicknesses, sheet resistances, and conductivities; refractive indices and extinction coefficients; functional layers in TMM simulations; simulated PCE and AVT; experimental data; photovoltaic parameters; charge carrier mobilities (PDF)

\section{AUTHOR INFORMATION}

\section{Corresponding Authors}

Yuxin Xia - Electronic and Photonic Materials (EFM), Department of Physics, Chemistry and Biology (IFM),
Linköping University, Linköping SE-58183, Sweden;

Email: yuxin.xia@uhasselt.be

Fengling Zhang - Electronic and Photonic Materials (EFM), Department of Physics, Chemistry and Biology (IFM), Linköping University, Linköping SE-58183, Sweden; ○ orcid.org/0000-0002-1717-6307;

Email: fengling.zhang@liu.se

\section{Authors}

Nannan Yao - Electronic and Photonic Materials (EFM), Department of Physics, Chemistry and Biology (IFM), Linköping University, Linköping SE-58183, Sweden; (1) orcid.org/0000-0002-9849-6117

Yanfeng Liu - Electronic and Photonic Materials (EFM), Department of Physics, Chemistry and Biology (IFM), Linköping University, Linköping SE-58183, Sweden

Shangzhi Chen - Laboratory of Organic Electronics, Department of Science and Technology (ITN), Linköping University, Norrköping SE-60174, Sweden; (1) orcid.org/ 0000-0002-7410-2531

Magnus P. Jonsson - Laboratory of Organic Electronics, Department of Science and Technology (ITN), Linköping University, Norrköping SE-60174, Sweden; (1) orcid.org/ 0000-0002-3002-3639

Complete contact information is available at:

https://pubs.acs.org/10.1021/acsaem.1c03017

\section{Notes}

The authors declare no competing financial interest.

\section{ACKNOWLEDGMENTS}

N.Y. and F.Z. acknowledge funding from the Knut and Alice Wallenberg foundation under Contract 2016.0059, the Swedish Government Research Area in Materials Science on Functional Materials at Linköping University (Faculty Grant SFO-Mat-LiU No. 200900971), and the China Scholarship Council (CSC; Grant No. 201708370115).

\section{REFERENCES}

(1) Henemann, A. BIPV: Built-in Solar Energy. Renewable Energy Focus 2008, 9, 14-19.

(2) Traverse, C. J.; Pandey, R.; Barr, M. C.; Lunt, R. R. Emergence of Highly Transparent Photovoltaics for Distributed Applications. Nat. Energy 2017, 2, 849-860.

(3) Ravishankar, E.; Booth, R. E.; Saravitz, C.; Sederoff, H.; Ade, H. W.; O'Connor, B. T. Achieving Net Zero Energy Greenhouses by Integrating Semitransparent Organic Solar Cells. Joule 2020, 4, 490506.

(4) Zhou, Y.; Li, F.; Barrau, S.; Tian, W.; Inganäs, O.; Zhang, F. Inverted and Transparent Polymer Solar Cells Prepared with Vacuum-Free Processing. Sol. Energy Mater. Sol. Cells 2009, 93, 497-500.

(5) Chen, K. S.; Salinas, J. F.; Yip, H. L.; Huo, L.; Hou, J.; Jen, A. K. Y. Semi-Transparent Polymer Solar Cells with 6\% PCE, 25\% Average Visible Transmittance and a Color Rendering Index Close to 100 for Power Generating Window Applications. Energy Environ. Sci. 2012, 5, 9551-9557.

(6) Chen, C.-C.; Dou, L.; Zhu, R.; Chung, C.-H.; Song, T.-B.; Zheng, Y. B.; Hawks, S.; Li, G.; Weiss, P. S.; Yang, Y. Visibly Transparent Polymer Solar Cells Produced by Solution Processing. ACS Nano 2012, 6, 7185-7190.

(7) Wang, D.; Liu, H.; Li, Y.; Zhou, G.; Zhan, L.; Zhu, H.; Lu, X.; Chen, H.; Li, C. Z. High-Performance and Eco-Friendly Semitransparent Organic Solar Cells for Greenhouse Applications. Joule 2021, 5, 945-957. 
(8) Yin, P.; Yin, Z.; Ma, Y.; Zheng, Q. Improving the Charge Transport of the Ternary Blend Active Layer for Efficient Semitransparent Organic Solar Cells. Energy Environ. Sci. 2020, 13, 51775185.

(9) Wang, D.; Qin, R.; Zhou, G.; Li, X.; Xia, R.; Li, Y.; Zhan, L.; Zhu, H.; Lu, X.; Yip, H. L.; Chen, H.; Li, C. Z. High-Performance Semitransparent Organic Solar Cells with Excellent Infrared Reflection and See-Through Functions. Adv. Mater. 2020, 32, 2001621.

(10) Upama, M. B.; Wright, M.; Elumalai, N. K.; Mahmud, M. A.; Wang, D.; Xu, C.; Uddin, A. High-Efficiency Semitransparent Organic Solar Cells with Non-Fullerene Acceptor for Window Application. ACS Photonics 2017, 4, 2327-2334.

(11) Xue, Q.; Xia, R.; Brabec, C. J.; Yip, H. L. Recent Advances in Semi-Transparent Polymer and Perovskite Solar Cells for Power Generating Window Applications. Energy Environ. Sci. 2018, 11, $1688-1709$.

(12) Yang, C.; Liu, D.; Bates, M.; Barr, M. C.; Lunt, R. R. How to Accurately Report Transparent Solar Cells. Joule 2019, 3, 1803-1809.

(13) Hu, Z.; Wang, J.; Ma, X.; Gao, J.; Xu, C.; Yang, K.; Wang, Z.; Zhang, J.; Zhang, F. A Critical Review on Semitransparent Organic Solar Cells. Nano Energy 2020, 78, 105376.

(14) Duan, L.; Hoex, B.; Uddin, A. Progress in Semitransparent Organic Solar Cells. Solar RRL 2021, 5, 2100041.

(15) Dou, L.; Chang, W. H.; Gao, J.; Chen, C. C.; You, J.; Yang, Y. A Selenium-Substituted Low-Bandgap Polymer with Versatile Photovoltaic Applications. Adv. Mater. 2013, 25, 825-831.

(16) Ji, G.; Wang, Y.; Luo, Q.; Han, K.; Xie, M.; Zhang, L.; Wu, N.; Lin, J.; Xiao, S.; Li, Y. Q.; Luo, L. Q.; Ma, C. Q. Fully Coated Semitransparent Organic Solar Cells with a Doctor-Blade-Coated Composite Anode Buffer Layer of Phosphomolybdic Acid and PEDOT:PSS and a Spray-Coated Silver Nanowire Top Electrode. ACS Appl. Mater. Interfaces 2018, 10, 943-954.

(17) Li, G.; Chu, C. W.; Shrotriya, V.; Huang, J.; Yang, Y. Efficient Inverted Polymer Solar Cells. Appl. Phys. Lett. 2006, 88, 253503.

(18) Chueh, C. C.; Chien, S. C.; Yip, H. L.; Salinas, J. F.; Li, C. Z.; Chen, K. S.; Chen, F. C.; Chen, W. C.; Jen, A. K. Y. Toward HighPerformance Semi-Transparent Polymer Solar Cells: Optimization of Ultra-Thin Light Absorbing Layer and Transparent Cathode Architecture. Adv. Energy Mater. 2013, 3, 417-423.

(19) Zhou, Y.; Zhang, F.; Tvingstedt, K.; Barrau, S.; Li, F.; Tian, W.; Inganäs, O. Investigation on Polymer Anode Design for Flexible Polymer Solar Cells. Appl. Phys. Lett. 2008, 92, 233308.

(20) Leenen, M. A. M.; Arning, V.; Thiem, H.; Steiger, J.; Anselmann, R. Printable Electronics: Flexibility for the Future. Phys. Status Solidi A 2009, 206, 588-597.

(21) Zhang, F.; Johansson, M.; Andersson, M. R.; Hummelen, J. C.; Inganäs, O. Polymer Photovoltaic Cells with Conducting Polymer Anodes. Adv. Mater. 2002, 14, 662-665.

(22) Kim, Y. H.; Sachse, C.; MacHala, M. L.; May, C.; MüllerMeskamp, L.; Leo, K. Highly Conductive PEDOT:PSS Electrode with Optimized Solvent and Thermal Post-Treatment for ITO-Free Organic Solar Cells. Adv. Funct. Mater. 2011, 21, 1076-1081.

(23) Yim, J. H.; Joe, S. Y.; Pang, C.; Lee, K. M.; Jeong, H.; Park, J. Y.; Ahn, Y. H.; De Mello, J. C.; Lee, S. Fully Solution-Processed Semitransparent Organic Solar Cells with a Silver Nanowire Cathode and a Conducting Polymer Anode. ACS Nano 2014, 8, 2857-2863.

(24) Liu, Z.; You, P.; Liu, S.; Yan, F. Neutral-Color Semitransparent Organic Solar Cells with All-Graphene Electrodes. ACS Nano 2015, 9, 12026-12034.

(25) Zhou, Y.; Cheun, H.; Choi, S.; Fuentes-Hernandez, C.; Kippelen, B. Optimization of a Polymer Top Electrode for Inverted Semitransparent Organic Solar Cells. Org. Electron. 2011, 12, 827831.

(26) Dyer, A. L.; Bulloch, R. H.; Zhou, Y.; Kippelen, B.; Reynolds, J. R.; Zhang, F. A Vertically Integrated Solar-Powered Electrochromic Window for Energy Efficient Buildings. Adv. Mater. 2014, 26, 48954900.
(27) Tong, J.; Xiong, S.; Zhou, Y.; Mao, L.; Min, X.; Li, Z.; Jiang, F.; Meng, W.; Qin, F.; Liu, T.; Ge, R.; Fuentes-Hernandez, C.; Kippelen, B.; Zhou, Y. Flexible All-Solution-Processed All-Plastic Multijunction Solar Cells for Powering Electronic Devices. Mater. Horiz. 2016, 3, 452-459.

(28) Tang, Z.; George, Z.; Ma, Z.; Bergqvist, J.; Tvingstedt, K.; Vandewal, K.; Wang, E.; Andersson, L. M.; Andersson, M. R.; Zhang, F.; Inganäs, O. Semi-Transparent Tandem Organic Solar Cells with 90\% Internal Quantum Efficiency. Adv. Energy Mater. 2012, 2, 14671476.

(29) Park, H.; Lee, J. H.; Lee, S.; Jeong, S. Y.; Choi, J. W.; Lee, C. L.; Kim, J. H.; Lee, K. Retarding Ion Exchange between Conducting Polymers and Ionic Liquids for Printable Top Electrodes in Semitransparent Organic Solar Cells. ACS Appl. Mater. Interfaces 2020, 12, 2276-2284

(30) Lee, D. J.; Heo, D. K.; Yun, C.; Kim, Y. H.; Kang, M. H. Solution-Processed Semitransparent Inverted Organic Solar Cells from a Transparent Conductive Polymer Electrode. ECS J. Solid State Sci. Technol. 2019, 8, Q32-Q37.

(31) Hu, Z.; Wang, Z.; An, Q.; Zhang, F. Semitransparent Polymer Solar Cells with $12.37 \%$ Efficiency and $18.6 \%$ Average Visible Transmittance. Sci. Bull. 2020, 65, 131-137.

(32) Hu, Z.; Wang, J.; Wang, Z.; Gao, W.; An, Q.; Zhang, M.; Ma, X.; Wang, J.; Miao, J.; Yang, C.; Zhang, F. Semitransparent Ternary Nonfullerene Polymer Solar Cells Exhibiting 9.40\% Efficiency and 24.6\% Average Visible Transmittance. Nano Energy 2019, 55, 424432.

(33) Shi, H.; Xia, R.; Zhang, G.; Yip, H. L.; Cao, Y. Spectral Engineering of Semitransparent Polymer Solar Cells for Greenhouse Applications. Adv. Energy Mater. 2019, 9, 1803438.

(34) Hou, J.; Inganas, O.; Friend, R. H.; Gao, F. Organic Solar Cells Based on Non-Fullerene Acceptors. Nat. Mater. 2018, 17, 119-128.

(35) Wang, J.; Yao, N.; Zhang, D.; Zheng, Z.; Zhou, H.; Zhang, F.; Zhang, Y. Fast Field-Insensitive Charge Extraction Enables High Fill Factors in Polymer Solar Cells. ACS Appl. Mater. Interfaces 2020, 12, 38460-38469.

(36) Yuan, J.; Zhang, Y.; Zhou, L.; Zhang, G.; Yip, H. L.; Lau, T. K.; Lu, X.; Zhu, C.; Peng, H.; Johnson, P. A.; Leclerc, M.; Cao, Y.; Ulanski, J.; Li, Y.; Zou, Y. Single-Junction Organic Solar Cell with over $15 \%$ Efficiency Using Fused-Ring Acceptor with ElectronDeficient Core. Joule 2019, 3, 1140-1151.

(37) Yao, N.; Wang, J.; Chen, Z.; Bian, Q.; Xia, Y.; Zhang, R.; Zhang, J.; Qin, L.; Zhu, H.; Zhang, Y.; Zhang, F. Efficient Charge Transport Enables High Efficiency in Dilute Donor Organic Solar Cells. J. Phys. Chem. Lett. 2021, 12, 5039-5044.

(38) Liu, Y.; Zhang, J.; Zhou, G.; Liu, F.; Zhu, X.; Zhang, F. Electric Field Facilitating Hole Transfer in Non-Fullerene Organic Solar Cells with a Negative HOMO Offset. J. Phys. Chem. C 2020, 124, 1513215139.

(39) Inganäs, O.; Zhang, F.; Tvingstedt, K.; Andersson, L. M.; Hellström, S.; Andersson, M. R. Polymer Photovoltaics with Alternating Copolymer/ Fullerene Blends and Novel Device Architectures. Adv. Mater. 2010, 22, E100-E116.

(40) Zhang, F.; Inganäs, O.; Zhou, Y.; Vandewal, K. Development of Polymer-Fullerene Solar Cells. Natl. Sci. Rev. 2016, 3, 222-239.

(41) Li, Z.; Qin, F.; Liu, T.; Ge, R.; Meng, W.; Tong, J.; Xiong, S.; Zhou, Y. Optical Properties and Conductivity of PEDOT:PSS Films Treated by Polyethylenimine Solution for Organic Solar Cells. Org. Electron. 2015, 21, 144-148.

(42) Xiong, Y.; Booth, R. E.; Kim, T.; Ye, L.; Liu, Y.; Dong, Q.; Zhang, M.; So, F.; Zhu, Y.; Amassian, A.; O’Connor, B. T.; Ade, H. Novel Bimodal Silver Nanowire Network as Top Electrodes for Reproducible and High-Efficiency Semitransparent Organic Photovoltaics. Solar RRL 2020, 4, 2000328.

(43) Guo, F.; Zhu, X.; Forberich, K.; Krantz, J.; Stubhan, T.; Salinas, M.; Halik, M.; Spallek, S.; Butz, B.; Spiecker, E.; Ameri, T.; Li, N.; Kubis, P.; Guldi, D. M.; Matt, G. J.; Brabec, C. J. ITO-Free and Fully Solution-Processed Semitransparent Organic Solar Cells with High Fill Factors. Adv. Energy Mater. 2013, 3, 1062-1067. 
(44) Guo, F.; Kubis, P.; Stubhan, T.; Li, N.; Baran, D.; Przybilla, T.; Spiecker, E.; Forberich, K.; Brabec, C. J. Fully Solution-Processing Route toward Highly Transparent Polymer Solar Cells. ACS Appl. Mater. Interfaces 2014, 6, 18251-18257.

(45) Wang, Y.; Jia, B.; Qin, F.; Wu, Y.; Meng, W.; Dai, S.; Zhou, Y.; Zhan, X. Semitransparent, Non-Fullerene and Flexible All-Plastic Solar Cells. Polymer 2016, 107, 108-112.

(46) Czolk, J.; Landerer, D.; Koppitz, M.; Nass, D.; Colsmann, A. Highly Efficient, Mechanically Flexible, Semi-Transparent Organic Solar Cells Doctor Bladed from Non-Halogenated Solvents. Adv. Mater. Technol. 2016, 1, 1600184.

(47) Koppitz, M.; Hesse, N.; Landerer, D.; Graf von Reventlow, L.; Wegner, E.; Czolk, J.; Colsmann, A. Organic Solar Modules: Fully Doctor Bladed on Glass in Air. Energy Technol. 2017, 5, 1105-1111. (48) Lucera, L.; Machui, F.; Schmidt, H. D.; Ahmad, T.; Kubis, P.; Strohm, S.; Hepp, J.; Vetter, A.; Egelhaaf, H. J.; Brabec, C. J. Printed Semi-Transparent Large Area Organic Photovoltaic Modules with Power Conversion Efficiencies of Close to 5\%. Org. Electron. 2017, 45, 209-214.

(49) Sun, X.; Zha, W.; Lin, T.; Wei, J.; Ismail, I.; Wang, Z.; Lin, J.; Luo, Q.; Ding, C.; Zhang, L.; Su, Z.; Chu, B.; Zhang, D.; Ma, C. Q. Water-Assisted Formation of Highly Conductive Silver Nanowire Electrode for All Solution-Processed Semi-Transparent Perovskite and Organic Solar Cells. J. Mater. Sci. 2020, 55, 14893-14906.

(50) Pettersson, L. A. A.; Roman, L. S.; Inganäs, O. Modeling Photocurrent Action Spectra of Photovoltaic Devices Based on Organic Thin Films. J. Appl. Phys. 1999, 86, 487-496.

(51) Byrnes, S. J. Multilayer Optical Calculations. arXiv Preprint (Computational Physics), 2016. arXiv:1603.02720. https://arxiv.org/ abs/1603.02720\#.

(52) Xia, R.; Gu, H.; Liu, S.; Zhang, K.; Yip, H. L.; Cao, Y. Optical Analysis for Semitransparent Organic Solar Cells. Solar RRL 2019, 3, 1800270 .

(53) Chen, Z.; Chen, X.; Qiu, B.; Zhou, G.; Jia, Z.; Tao, W.; Li, Y.; Yang, Y. M.; Zhu, H. Ultrafast Hole Transfer and Carrier Transport Controlled by Nanoscale-Phase Morphology in Nonfullerene Organic Solar Cells. J. Phys. Chem. Lett. 2020, 11, 3226-3233.

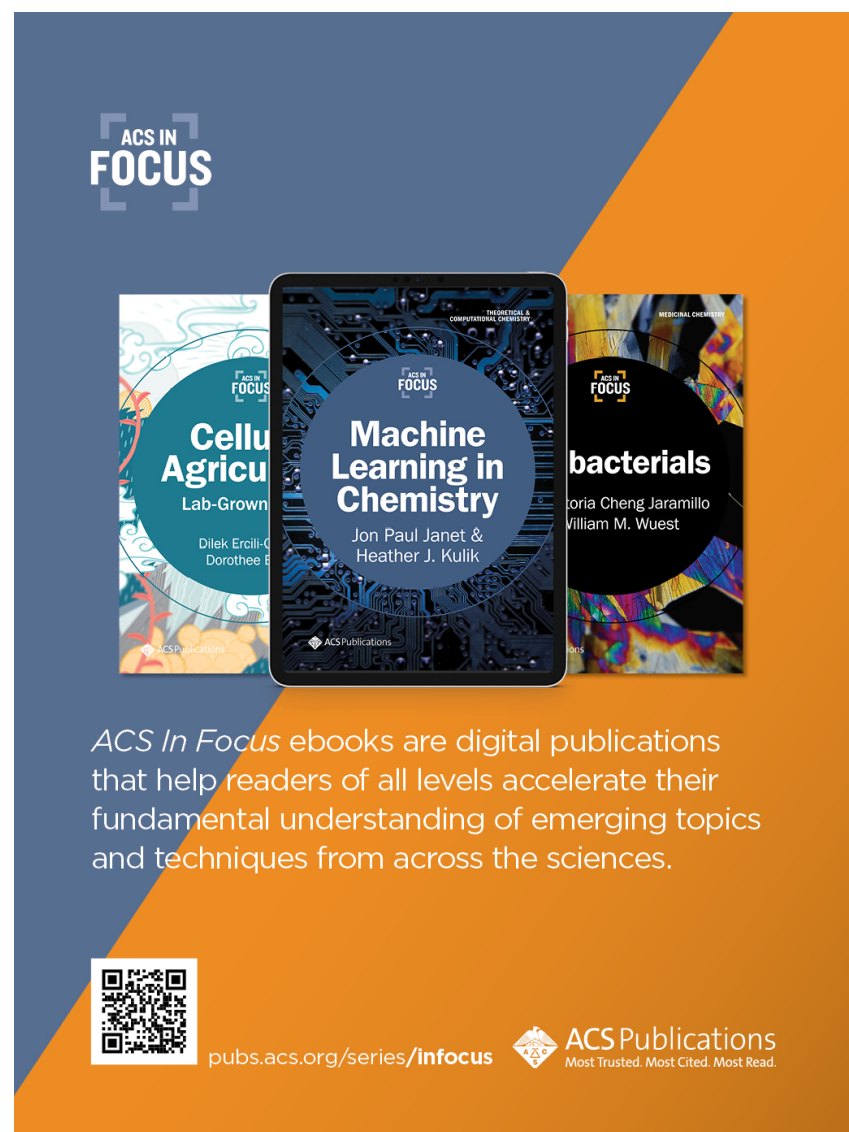

